\title{
Rac1 Induces the Clustering of AMPA Receptors during Spinogenesis
}

\author{
Katie M. Wiens, Hang Lin, and Dezhi Liao \\ Department of Neuroscience, The University of Minnesota, Minneapolis, Minnesota 55455
}

Glutamatergic synapses switch from nonspiny synapses to become dendritic spines during early neuronal development. Here, we report that the lack of sufficient Rac1, a small RhoGTPase, contributes to the absence of spinogenesis in immature neurons. The overexpression of green fluorescence protein-tagged wild-type Racl initiated the formation of dendritic spines in cultured dissociated hippocampal neurons younger than $11 \mathrm{~d}$ in vitro, indicating that Racl is likely one of the missing pieces responsible for the lack of spines in immature neurons. The overexpression of wild-type Racl also induced the clustering of AMPA receptors (AMPARs) and increased the amplitude of miniature EPSCs (mEPSCs). The expression of constitutively active Rac1 induced the formation of unusually large synapses with large amounts of AMPAR clusters. Also, our live imaging experiments revealed that the contact of an axon induced the clustering of Rac1, and subsequent morphological changes led to spinogenesis. Additionally, the overexpression of wild-type Racl and constitutively active Rac1 increased the size of preexisting spines and the amplitude of mEPSCs in mature neurons ( $>21 \mathrm{~d}$ in vitro) within $24 \mathrm{~h}$ after transfection. Together, these results indicate that activation of Racl enhances excitatory synaptic transmission by recruiting AMPARs to synapses during spinogenesis, thus providing a mechanistic link between presynaptic and postsynaptic developmental changes. Furthermore, we show that Racl has two distinct roles at different stages of neuronal development. The activation of Racl initiates spinogenesis at an early stage and regulates the function and morphology of preexisting spines at a later stage.

Key words: synaptogenesis; Racl; glutamate receptor; dendritic spine; AMPA receptor; synaptic plasticity; Rho GTPase

\section{Introduction}

More than $90 \%$ of excitatory synaptic transmission in the brain occurs at dendritic spines (Harris and Kater, 1994; Nimchinsky et al., 2002). Dendritic spines are mushroom-like, membranous protrusions from dendrites and are important in normal cognitive function and neuronal development (Kennedy, 2000; Nimchinsky et al., 2002). The morphology of these spines is a strong determinant of their function, and the actin cytoskeleton is believed to be the basic structural foundation that is responsible for their shape (Shirao and Sekino, 2001; Nimchinsky et al., 2002). Three Rho GTPases [RhoA, Cdc42 (cell division cycle 42), and Rac1] modulate the actin cytoskeleton in fibroblasts, budding yeast, and neurons and are believed to be the major regulators of spine morphogenesis (Adams et al., 1990; Ridley et al., 1992; Nakayama et al., 2000; Carlisle and Kennedy, 2005). Guanine nucleotide exchange factors (GEFs), which activate these three Rho GTPases, are also known to affect the morphology of spines. For example, Kalirin-7, a GEF for Rac1, interacts with PDZ (postsynaptic density-95/Discs large/zona occludens-1) domain proteins and regulates the density and morphology of dendritic spines (Penzes et al., 2001). GEFT, a Rho family GEF, can also regulate the formation of dendritic spines (Bryan et al., 2004).

Received May 16, 2005; revised 0ct. 5, 2005; accepted 0ct. 5, 2005

This work was supported by a grant from the Whitehall Foundation, a grant from the McManus Trust for Drug Abuse, and a grant from the Minnesota Medical Foundation to D.L. We thank Drs. George Wilcox, Lance Zirpel, Janet Dubinsky, and Paul Letourneau for their helpful comments, Gillian Schivone and Eric J. Nordstrom for their technical support, and Dr. Hollis Cline for Rac1 constructs.

Correspondence should be addressed to Dr. Dezhi Liao, Assistant Professor, Department of Neuroscience, The University of Minnesota, 321 Church Street Southeast, Minneapolis, MN 55455. E-mail: liaox020@tc.umn.edu.

DOI:10.1523/JNEUROSCI.1947-05.2005

Copyright $\odot 2005$ Society for Neuroscience ～0270-6474/05/2510627-10\$15.00/0
Furthermore, the Rac/p21-activated kinase (PAK) signaling pathway regulates spine morphogenesis in both intact animals and cultured neurons (Hayashi et al., 2004; Zhang et al., 2005). All of these previous studies overwhelmingly show that Racl is a significant modulator of spine morphology. However, a detailed analysis of how Racl affects the function of dendritic spines has not yet been reported. In this study, we found that the overexpression of wild-type and constitutively active Racl enhanced excitatory synaptic transmission and induced the clustering of AMPA receptors (AMPARs) in both preexisting and newly formed dendritic spines, indicating that Racl can regulate the function of excitatory synapses.

Previous studies showed that neurons start to possess dendritic spines after postnatal day 7 (P7) in intact animals and after $14 \mathrm{~d}$ in vitro (DIV) in cultured dissociated neurons (Harris and Kater, 1994; Rao and Craig, 1997; Nimchinsky et al., 2002). Many molecules are reported to modulate the density and morphology of spines, but the molecular mechanism underlying this delayed onset of spinogenesis is yet unknown (Luo, 2000; Shirao and Sekino, 2001; Nimchinsky et al., 2002). Surprisingly, we found that the overexpression of wild-type Racl (Racw) induced the formation of spines in immature neurons as early as 7 DIV. This unexpected result led us to test the hypothesis that Rac1 initiates the formation of dendritic spines. Additional research in this study provides direct evidence that Racl participates in spinogenesis and recruits AMPARs to newly formed spines via activation of Cdc42 or Rac interactive binding (CRIB) motifcontaining proteins such as PAK. In our live imaging experiments, the contact of axons induced the clustering of green fluorescence protein (GFP)-tagged wild-type Rac1 molecules, 
and subsequent morphological changes led to the formation of dendritic spines. These results effectively provide a mechanistic link between presynaptic and postsynaptic changes during the creation of new spines and produce a valuable molecular model for this spinogenesis.

\section{Materials and Methods}

Neuronal cultures and transfection. A $25 \mathrm{~mm}$ glass coverslip (thickness, $0.08 \mathrm{~mm}$ ) was glued over a $22 \mathrm{~mm}$ hole in the bottom of a $35 \mathrm{~mm}$ tissue-culture dish using silicone sealant as described previously (Lin et al., 2004). Dissociated neuronal cultures from rat hippocampi at P1-P2 were prepared as described previously (Liao et al., 2001). Neurons were plated onto prepared $35 \mathrm{~mm}$ tissue culture dishes at a density of $1 \times 10^{6}$ cells per dish. The age of cultured neurons was counted from the day of plating (day 1 in vitro). To label dendrites, neurons at 5-7 DIV were transfected with plasmids encoding enhanced GFP (EGFP) (driven by a cytomegalovirus promoter; referred to as GFP; Clontech, Cambridge, UK), Racw, Rac1N17 (dominant negative; referred to as Rac-), or Rac1V12 (constitutively active; referred to as Rac+). All of the above Racl constructs were tagged to enhanced GFP and have been used and characterized previously ( $\mathrm{Li}$ et al., 2002). To test whether the interaction between Racl and CRIB motif-containing proteins is important during spinogenesis, we used a mutant of Racl, Rac1Y40K (referred to as Rac40), that was tagged with EGFP. Rac40 was made with PCR sitedirected mutagenesis. The standard calcium phosphate precipitation method was used to transfect neurons at 5-7 DIV (Liao et al., 2005), whereas the gene gun technique was used to transfect neurons at 21 DIV (Wellmann et al., 1999). The culture dishes fit tightly in a homemade holding chamber on a fixed platform above an inverted microscope sitting on an $X-Y$ translation stage (Burleigh Instruments, Fishers, NY). The location of any neuron of interest was determined by the reading of the $X-Y$ translation stage, and neurons could be found again in the next observation using the $X--Y$ coordinates (accuracy, $4 \mu \mathrm{m}$ ). In live imaging experiments that lasted several hours, the holding chamber was heated to $37^{\circ} \mathrm{C}$ and was gassed with $5 \% \mathrm{CO}_{2}$ and $95 \%$ air. Time-lapse images of the same neurons were taken every $15 \mathrm{~min}$.

Immunocytochemistry and Western blots. As described previously (Liao et al., 1999), cultured neurons were fixed and permeabilized successively with $4 \%$ paraformaldehyde, $100 \%$ methanol, and $0.2 \%$ Triton X-100. Antibodies against the $\mathrm{C}$ termini of glutamate receptor 1 (GluR1) and GluR2/3 subunits were added together to detect AMPARs (fluorescent dye-conjugated rabbit antibodies), and a mouse anti-synaptophysin antibody was used to label presynaptic termini. To label surface AMPARs, live neurons were incubated in media containing a polyclonal rabbit antibody against the extracellular $\mathrm{N}$ terminus of the GluR1 subunit at $37^{\circ} \mathrm{C}$ for $1-2 \mathrm{~h}$ and were subsequently fixed and incubated with a rhodamine-conjugated secondary anti-rabbit antibody (O'Brien et al., 1997). A commercially available mouse anti-Racl antibody (Chemicon, Temecula, CA) was used to detect endogenous Rac1 in Western blots and in immunocytochemistry. Western blot experiments were performed as described previously (Liao et al., 2001). Briefly, cultured neurons were lysed in modified radioimmunoprecipitation assay buffer ( $1 \%$ Triton X-100, 0.1\% SDS, 0.5\% deoxycholic acid, $10 \mathrm{~mm} \mathrm{NaPO}_{4}, 150 \mathrm{~mm} \mathrm{NaCl}$, 2 mм EDTA, $50 \mathrm{~mm} \mathrm{NaF}, 10 \mathrm{~mm}$ sodium pyrophosphate, $10 \mathrm{~mm}$ iodoacetamide, $1 \mathrm{~mm}$ sodium orthovanadate, and $1 \mathrm{~mm}$ phenylmethylsulfonyl fluoride plus $2 \mu \mathrm{g} / \mathrm{ml}$ aprotinin, $1 \mu \mathrm{g} / \mathrm{ml}$ leupeptin, $2 \mu \mathrm{g} / \mathrm{ml}$ antipain, and $10 \mu \mathrm{g} / \mathrm{ml}$ benzamide) on ice and then harvested with a cell scraper. The same amount of protein was loaded in each lane, and a mouse anti-actin monoclonal antibody (Chemicon) was used as a control.

Electrophysiology. Miniature EPSCs (mEPSCs) were recorded from cultured hippocampal neurons that had been transfected with plasmids encoding GFP-tagged molecules (Liao et al., 2005). Visual fields were moved randomly to approximate the center of the culture dish. Attempts were made to patch the first transfected neuron that was found. If the establishment of whole-cell configuration was not successful, a second transfected neuron was attempted. No more than two neurons were recorded from the same culture dish. Miniature EPSCs were recorded at holding potentials of -55 to $-60 \mathrm{mV}$ and filtered at $1 \mathrm{kHz}$. Input and series resistances were checked before and after the recording of mEPSCs, which lasted $\sim 10-30 \mathrm{~min}$. There was no significant difference in the series or input resistances among various groups of experiments. One recording sweep lasting $200 \mathrm{~ms}$ was sampled for every $1 \mathrm{~s}$. Miniature EPSCs were recorded in cultured dissociated neurons in standard Earle's balanced salts solution at room temperature with $200 \mu \mathrm{M} 2$-amino-5phosphonopentanoic acid (NMDA receptor blocker; D,L-form; active form would be $100 \mu \mathrm{M}$ ), $1 \mu \mathrm{M}$ tetrodotoxin (TTX; sodium channel blocker), and $100 \mu \mathrm{M}$ picrotoxin (GABA receptor blocker), gassed with $95 \%$ air and $5 \% \mathrm{CO}_{2}$. To increase the number of mEPSCs, an extra $2 \mathrm{~mm}$ $\mathrm{Ca}^{2+}$ and $1 \mathrm{~mm} \mathrm{Mg}^{2+}$ were added to the bath solution. The internal solution in the patch pipette contained the following (in mM): 100 cesium gluconate, 0.2 EGTA, 0.5 $\mathrm{MgCl}_{2}$, 2 ATP, $0.3 \mathrm{GTP}$, and 40 HEPES, pH 7.2 with $\mathrm{CsOH}$. All mEPSCs were analyzed with a program designed by Synaptosoft (Decatur, GA). Detection criteria for mEPSCs included peak amplitudes $>3 \mathrm{pA}$, a fast rise time, and a slow decay time. The time course and amplitude of every detected mEPSC were calculated, and parameters of all mEPSCs in each neuron were further averaged and treated as single samples.

Image analysis. Neurons transfected with various GFP-tagged constructs were photographed immediately after the electrophysiological recording (see above, Electrophysiology, for the selection of neurons). All digital images were analyzed with MetaMorph Imaging System (Universal Imaging Corporation, West Chester, PA), as described previously (Liao et al., 2005). Unless stated otherwise, all images of live neurons were taken as stacks and were averaged into one image before further analysis. In addition to simple averaging, stacks of images were also processed by deconvolution analyses using the MetaMorph software with the nearest planes. A stack of deconvoluted images was further averaged into one single image. A dendritic protrusion with an expanded head that was $50 \%$ wider than its neck was defined as a spine. The number of spines or nonspine protrusions from one neuron was counted manually and normalized per $100 \mu \mathrm{m}$ dendritic length. One-way ANOVA was used for comparison between multiple groups of data ( $n$, sample size, the number of neurons; $p<0.05$, significant). If the ANOVA test indicated that there were significant differences between parameters, group $t$ tests were used to further test the significance of the changes. If a difference passed the ANOVA test and the $t$ test $(p<0.05)$, we considered this change to be statistically significant. To highlight dendritic protrusions and spines in the measurement of protrusion size (see Fig. 6C), detection threshold was set at $75 \%$ of the fluorescent intensity in the center of the dendritic spine to be measured. The spine was separated manually from the dendrite using the line tool, and the area of highlighted dendritic spines was measured by the MetaMorph program. All data are reported as mean \pm SE. ${ }^{\star} p<0.05 ;{ }^{* *} p<0.01 ;{ }^{* *} p<0.001$.

\section{Results}

\section{Racl induces spinogenesis in immature neurons}

Cultured dissociated hippocampal neurons rarely have dendritic spines until 14 DIV (Rao and Craig, 1997). To determine which molecule might contribute to the delayed onset of spinogenesis, we screened several molecules including CaM kinase II, GluR1, GluR2, NMDA receptor subunit NR1, NR2A, Rac1, Cdc42, and RhoA. We tested whether the overexpression of these wild-type molecules could compensate for their deficiency early in development and thus initiate spinogenesis. Surprisingly, only wildtype Racl can initiate spinogenesis by overexpression alone. To test whether Racl can initiate the formation of dendritic spines, neurons at 6 DIV were transfected with plasmids encoding enhanced GFP (GFP), wild-type Racl (Racw), Rac1N17 (Rac-), and RaclV12 (Rac+) (nine neurons in each group). All of the Rac1 constructs were tagged with GFP and have been characterized previously (Li et al., 2002). To examine both the morphology and function of excitatory synapses, miniature EPSCs were recorded in cultured dissociated hippocampal neurons at 7-11 DIV, and live images of the neurons were taken after the recording (Fig. 1A). Neurons were then fixed immediately and perme- 


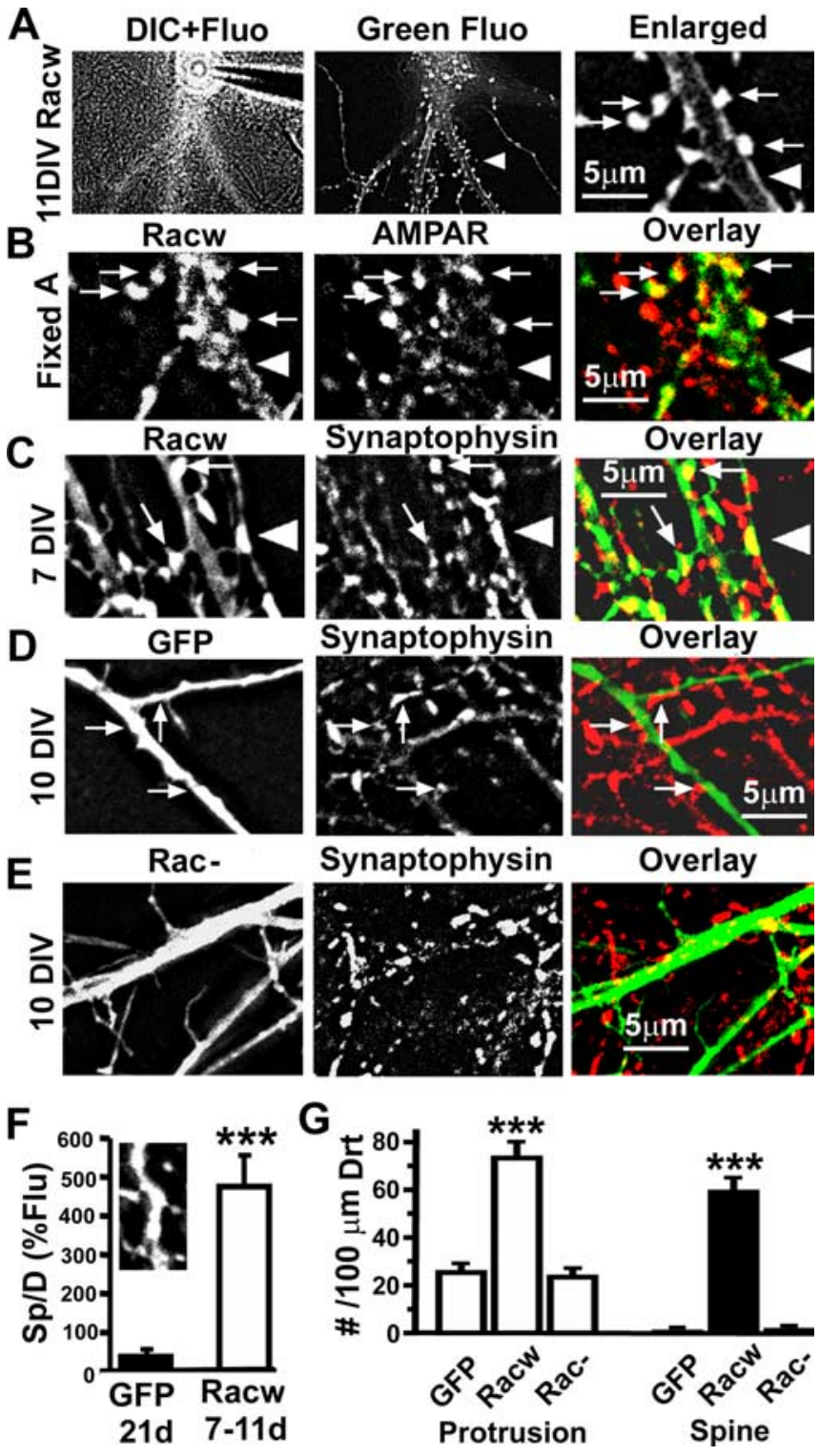

Figure 1. Expression of wild-type Rac1 induced the formation of dendritic spines early in development. $\boldsymbol{A}$, Left, An 11-d-old neuron expressing Racw was photographed when both illumination light and green fluorescent light were on. Middle, Only fluorescent light was on. The arrowhead denotes the enlarged area of the right panel. Right, A zoom-in image of the middle panel. The arrows point to dendritic spines, and the arrowhead indicates Racw clustering at the periphery of the dendrite. DIC, Differential interference contrast; Fluo, fluorescence. $\boldsymbol{B}-\boldsymbol{E}$, Neurons expressing $\operatorname{Racw}(\boldsymbol{B}, \boldsymbol{C} ; \boldsymbol{B}$ is the fixed neuron from $\boldsymbol{A}), \operatorname{GFP}(\boldsymbol{D})$, and $\operatorname{RaC}-(\boldsymbol{E})$ were stained with antibodies against AMPARs (anti-GluR1 and anti-GluR2/3 were added together; $\boldsymbol{B}$ ) or synaptophysin $(\boldsymbol{C}-\boldsymbol{E})$. The arrows indicate AMPAR $(\boldsymbol{B})$ or synaptophysin $(\boldsymbol{C}-\boldsymbol{E})$ clusters. $\boldsymbol{F}$, Ratio of the fluorescence (Flu) intensity in the center of a spine versus the center of the dendrite from which the spine grew $(\mathrm{Sp} / \mathrm{D})$. A value $>100 \%$ means that the spine is brighter than the dendrite. Inset, The middle of the dendrite is brighter than spines in a 3-week-old GFP-labeled neuron. $\mathbf{G}$, The density of dendritic protrusions and spines per $100 \mu \mathrm{m}$ dendrite (Drt) was measured in neurons expressing GFP, Racw, and Rac - . Error bars represent SE. ${ }^{* * *} p<0.001$.

abilized for immunocytochemistry and relocated for later morphological studies using an $X-Y$ translation stage, as described previously (Lin et al., 2004; Liao et al., 2005). Postsynaptic AMPARs were detected using antibodies against GluR1 and GluR2/3 subunits (Fig. $1 B$ ), whereas presynaptic termini were labeled using an antibody against synaptophysin (see Materials and Methods) (Fig. 1C). Racw induced the formation of dendritic spines in neurons as young as 7 DIV (Fig. $1 C$ ) and clustered in the heads of dendritic spines (Fig. 1A,C,F). The expression of Racw significantly increased the density of dendritic protrusions threefold and the density of spines 200-fold (number per $100 \mu \mathrm{m}$ length of dendrites; $p<0.001 ; n=9$ in each group; compared with control GFP) (Fig. $1 G$ ). The Racw clusters colocalized with synaptophysin proteins (Fig. 1C) and AMPARs (Fig. $1 B$ ), indicating that Racl-induced dendritic spines were part of glutamatergic synapses. In contrast, dendritic spines rarely formed in GFP-labeled neurons that were younger than 11 DIV (Fig. $1 D, G$ ). The expression of Rac - had no significant effect on the density of dendritic protrusions and spines in comparison with control GFP neurons (Fig. $1 E, G$ ), suggesting that the activity of Racl is low under normal conditions in young neurons.

Rac1 regulates the function of excitatory synapses in immature neurons

As seen in Figure 1, Racw was able to cluster AMPARs at glutamatergic synapses. To determine whether the AMPARs at these synapses are functional, we recorded AMPAR-mediated mEPSCs from neurons 7-11 DIV expressing Racw, Rac+, Rac-, or GFP. The expression of Racw and Rac + significantly increased the amplitude of mEPSCs by 96 and 149\%, respectively $(n=9$ in each group; $p<0.001$ ) (Fig. $2 A, C$ ). However, only Rac + significantly increased the rise time (by $45 \%$; $p<0.05$ ) (Fig. $2 E$ ) and decay time (by $85 \%$; $p<0.01$ ) (Fig. $2 F$ ), which is mainly attributable to the regular appearance of unusually large and wide mEPSCs in neurons expressing this construct (Fig. $2 \mathrm{~B}$ ). These unusually large mEPSCs often had amplitudes $>50 \mathrm{pA}$ and time courses $>80 \mathrm{~ms}$. The appearance of these unusually large mEPSCs is puzzling, because most dendrites of neurons expressing Rac+ rarely had mushroom-like spines (Fig. 2G). Instead, consistent with previous studies, numerous lamellipodia lacking presynaptic termini extended from the dendrites of Rac + neurons (Fig. 2G, arrowhead) (Pilpel and Segal, 2004). Interestingly, $\mathrm{Rac}+$ molecules were intensely clustered in proximal dendrites and the soma, which were innervated by many presynaptic termini (Fig. 2G, arrow). The clustering of Rac + molecules in proximal dendrites and the soma induced the formation of unusually large clusters of AMPARs (Fig. $2 H$, arrowheads). Furthermore, large clusters of Rac+ often contacted several synaptophysin clusters (Fig. $2 I$, arrows), indicating that continuous activation of Racl can induce the formation of "giant" synapses containing large amounts of clustered AMPARs and innervated by several presynaptic termini. These giant synapses might be the structural basis for the unusually large mEPSCs encountered in neurons expressing $\mathrm{Rac}+$. These results also indicate that constitutive activation of Racl can increase the amount of AMPARs per synapse, possibly by increasing the anchoring sites for AMPARs through remodeling of the actin cytoskeleton. Consistent with the increase in spine density as shown in Figure 1, the expression of Racw significantly increased both the frequency (by $81 \%$ ) and amplitude (by 96\%) of mEPSCs (Fig. $2 A, C, D$ ) without affecting their time courses (Fig. $2 E, F$ ). In contrast to Rac + , expression of Racw increased the frequency of mEPSCs, indicating the necessity for Racl to switch between an active and an inactive state to induce the proper formation of dendritic spines and subsequent AMPAR trafficking. Unexpectedly, Rac- did not significantly reduce the amplitude or frequency of mEPSCs in these immature neurons (Fig. $2 A, C-F$ ). This result is potentially caused by the low expression level of endogenous Racl early in development (see Fig. 5). In order for Rac - to have an effect, there has to be a relatively high level of normal activity. As shown in Figure 6I-M, 


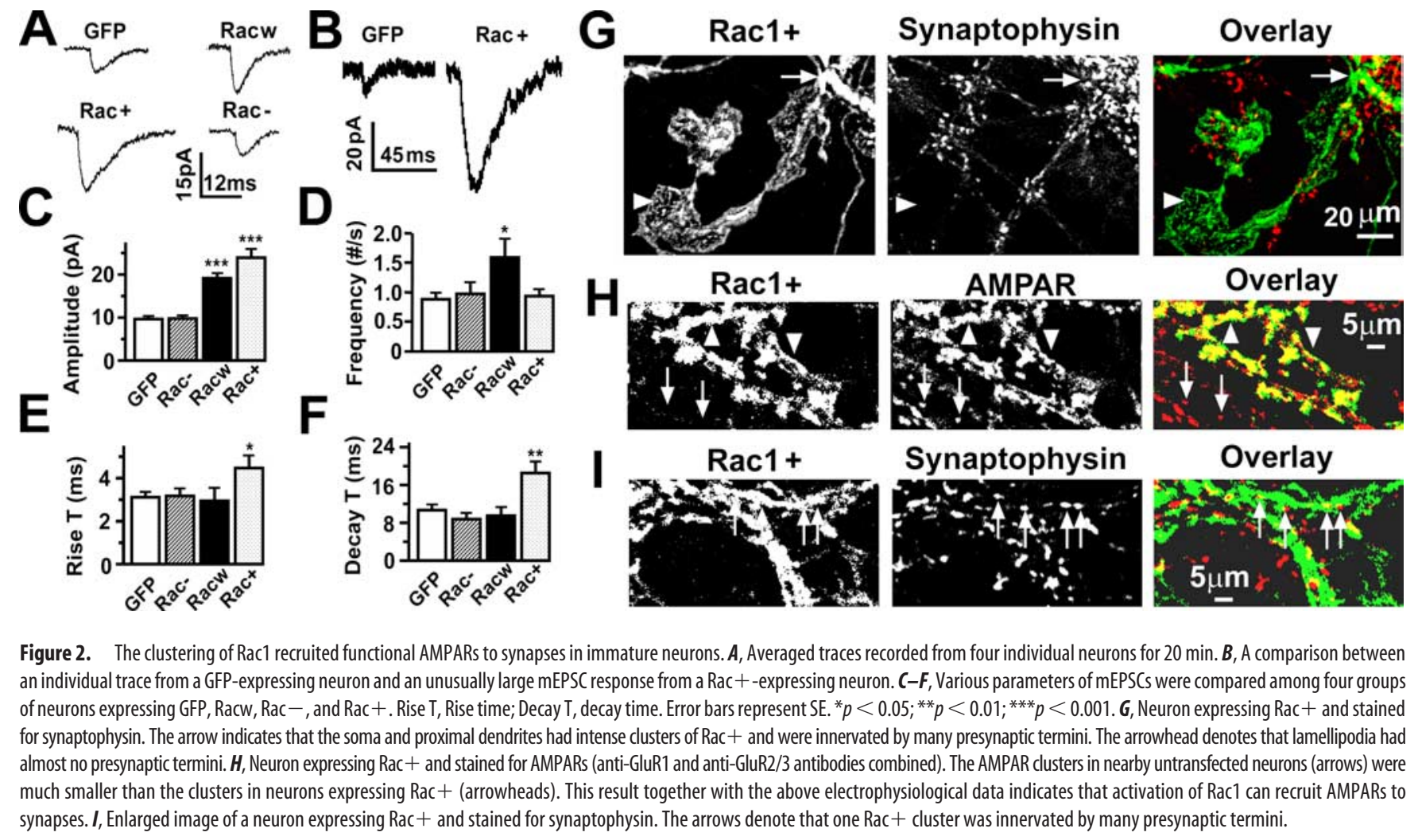

Rac - does in fact reduce the amplitude of mEPSCs at 17-21 DIV, when the normal expression of Racl is high.

Rac1 induces the clustering of surface AMPARs

As shown in Figures 1 and 2, the expression of Racw and Rac+ increased the amplitude of mEPSCs and induced the clustering of AMPARs, indicating that the activation of Racl enhances excitatory synaptic transmission by recruiting functional AMPARs to synapses. To test whether Racl can induce the clustering of surface AMPARs, neurons expressing GFP, Racw, Rac-, or Rac+ were immunostained with an affinity-purified rabbit polyclonal antibody against the extracellular $\mathrm{N}$ terminus of the GluR1 subunit, as described previously (O'Brien et al., 1997; Liao et al., 1999). The antibody was applied to live, unpermeabilized neurons to detect the presence of surface AMPARs. The clusters of Racw (Fig. 3A,B) and Rac+ (Fig. 3E) colocalized with clusters of surface AMPARs. Racw and Rac + significantly increased the number of surface AMPARs per $100 \mu \mathrm{m}$ dendrite and also increased the percentage of protrusions containing surface AMPARs (Fig. $3 F, G$ ). Surface AMPARs per $100 \mu \mathrm{m}$ dendrite of $\mathrm{Rac}+$ were counted at the proximal dendrites (Fig. $3 E, F$ ) because of the large lamellipodial formations at the distal portions (Fig. 2). These results further support that the activation of Rac1 can induce the clustering of AMPARs. Consistent with the results in Figure 2, Rac- was not able to decrease the number of surface AMPARs in neurons at $10 \mathrm{DIV}$, again indicating that normal expression of Racl at this stage in development is too low for changes to be evident when Racl activity is disrupted.

Temporal steps in Rac1-dependent spinogenesis

To understand how Racl initiates the formation of dendritic spines at such a young age, neurons at 6 DIV were transfected with GFP, Racw, Rac- , and Rac+ and were examined $8 \mathrm{~h}$ after transfection. Racw and $\mathrm{Rac}+$ were concentrated in the periphery of dendritic spines (Fig. $4 A$, arrowheads), as seen by a significant increase in the ratio of the fluorescence intensity in the periphery versus the center of dendrites $(p<0.001 ; n=7$ in each group; compared with control GFP neurons) (Fig. $4 C$ ). The expression of Rac - blocked the mobilization of Racl to the periphery (Fig. $4 A, C)$, and neurons expressing Rac - started to have granules in the soma and proximal dendrites $3 \mathrm{~d}$ after transfection (Fig. $4 B$ ). The proportion of neurons containing granules progressively increased over time (days after transfection; $n=7$ dishes) (Fig. $4 D$ ). It has been reported previously that Racl and other GTPases possess a CAAX sequence at their $\mathrm{C}$ terminus. After geranylgeranylation of this region, activated Racl is able to associate with the cell membrane (Hori et al., 1991; Hoffman et al., 2000). However, guanine nucleotide dissociation inhibitors (GDIs) are able to bind to inactive Racl and prevent the insertion of Racl into the plasma membrane and are also able to remove and inactivate Racl that is already at the membrane (Hori et al., 1991; Hoffman et al., 2000; Symons and Settleman, 2000; Robbe et al., 2003). Thus, our results suggest that Rac- is sequestered in the cytoplasm by GDIs and is not able to localize to the membrane.

The efficiency of Racw in inducing the formation of spines is striking. It took only $24 \mathrm{~h}$ for Racw to increase the density of spines by $92 \%$ ( $n=7 ; p<0.001$; from 8 to $32 \mathrm{~h}$ after transfection $)$ (Fig. $4 E$, black bars). The density of dendritic spines $32 \mathrm{~h}$ after the transfection of Racw reached the same level as in control GFP neurons at 21 DIV (Fig. $4 E$, open bars). The expression of Racsuppressed and delayed the formation of dendritic spines (Fig. $4 E$, hatched bars), indicating that the initiation of spinogenesis requires the activation of Racl during the early stage of neuronal development. However, dendritic spines can still be formed at a much lower density at 21 DIV, suggesting that other Rac1independent mechanisms might also participate in spinogenesis in the late stage of neuronal development.

The high efficiency of Racw in spinogenesis has enabled us to 

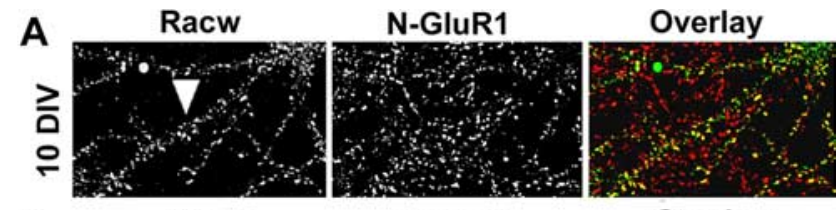

B

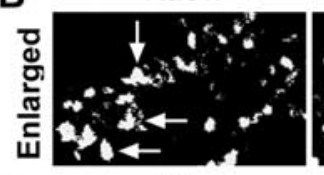

N-GluR1

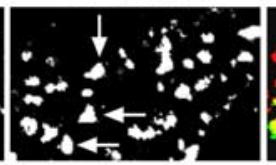

Overlay
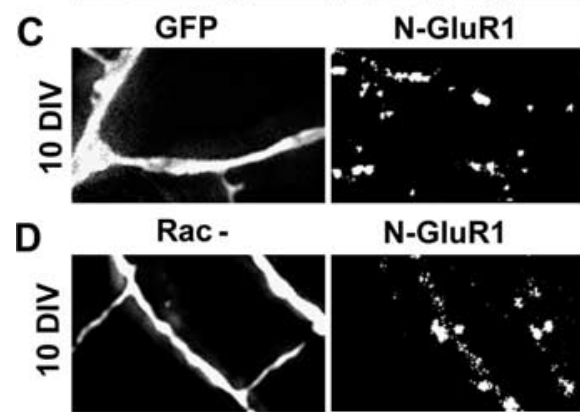

N-GluR1
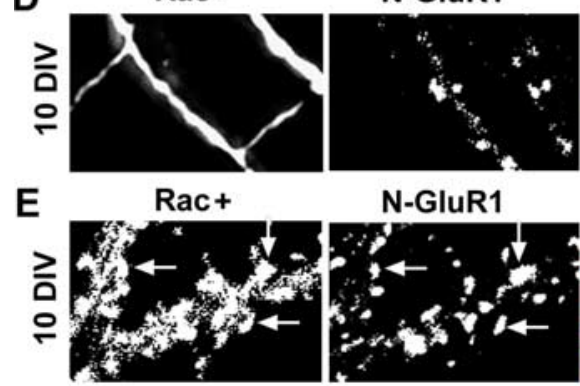

N-GluR1
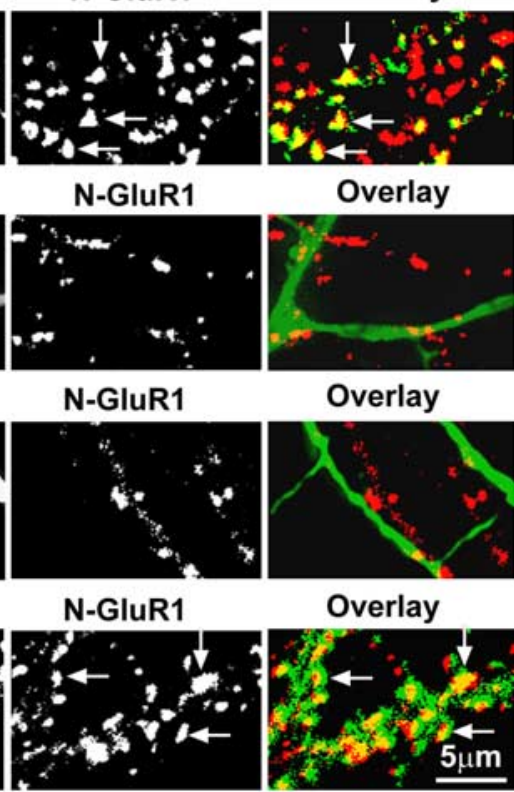

Overlay

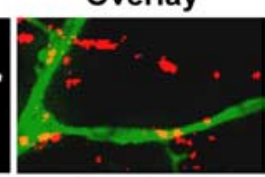

Overlay

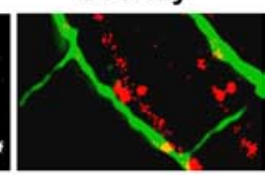

Overlay
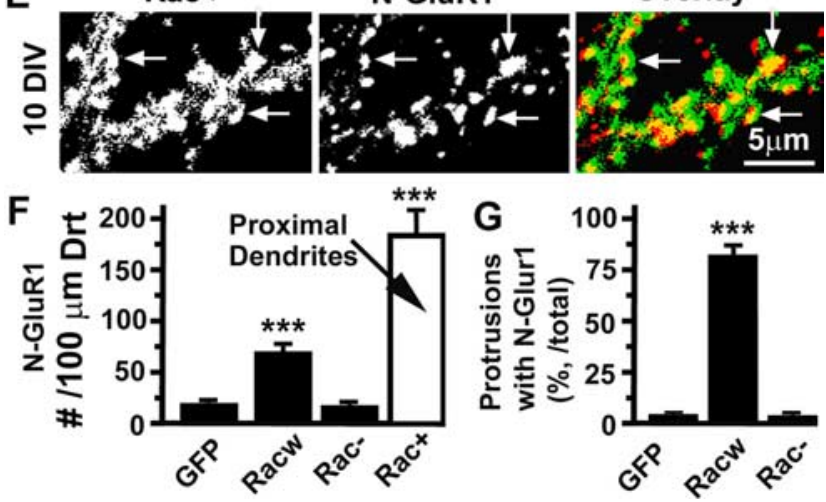

Figure 3. Rac1 induces the clustering of surface AMPARs. $\boldsymbol{A}$, Neurons expressing Racw were immunostained for surface AMPARs using an antibody against the extracellular $N$ terminus of the GluR1 subunit. The arrowhead indicates the enlarged area for $\boldsymbol{B}$. $\boldsymbol{B}$, Enlarged image from $\boldsymbol{A}$ showing that Racw clusters colocalized with AMPAR clusters (arrows). $\boldsymbol{C}-\boldsymbol{E}$, Neurons expressing GFP, $\operatorname{Rac}-$, and Rac + were immunostained with the same antibody used in $\boldsymbol{A}$. The arrows in $\boldsymbol{E}$ indicate that the soma and proximal dendrites in neurons expressing $\mathrm{Rac}+$ contained numerous large AMPAR clusters. N-GluR1, N terminus of the GluR1 subunit. $\boldsymbol{F}$, Quantification of the number of surface AMPAR clusters per $100 \mu \mathrm{m}$ dendrite (Drt). AMPARs were counted in the proximal dendrites of neurons expressing $\operatorname{Rac}+$. G, Quantification of the percentage of protrusions that colocalized with surface AMPAR staining indicates that Racw is also able to induce the clustering of AMPARs at dendritic spines. Error bars represent SE. ${ }^{* * *} p<0.001$.

observe how the contact of an axon initiates the formation of dendritic spines. Neurons were transfected with Racw for $8 \mathrm{~h}$ and were then put into a holding chamber at $37^{\circ} \mathrm{C}$ and imaged every $15 \mathrm{~min}$ (Fig. $4 F$ ). The contact of an axon (Fig. $4 F$, first and second panels, bottom arrow, 0 min) induced the clustering of Racl in the periphery of dendrites (Fig. $4 F$, top arrow, 0 min). The fluorescence of the Racl cluster progressively increased within 30 min, and subsequent morphological changes pushed both the Racl cluster and the axon away from the dendrite (Fig. $4 F$, bottom arrows, 15-30 $\mathrm{min}$ ). The diameter of the spine neck also increased over time (Fig. $4 F$, top arrows, $15 \mathrm{~min}$ to $1.5 \mathrm{~h}$ ), leading to the eventual formation of a mushroom-like spine with intensely clustered Racl in the spine head (1.5 h).

It has been reported widely that synaptic activity can modulate the function and morphology of dendritic spines by activity-
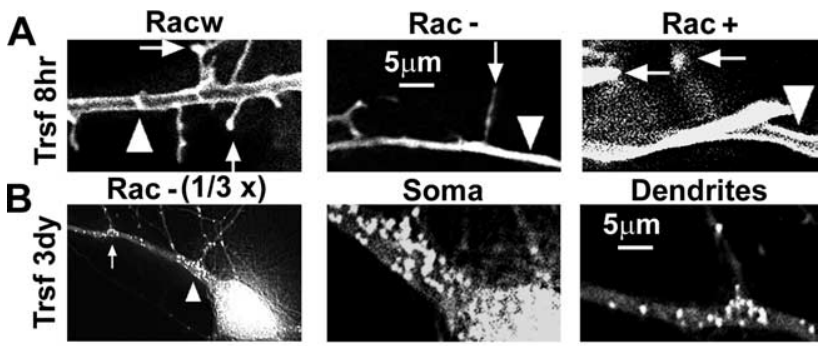

\section{C}
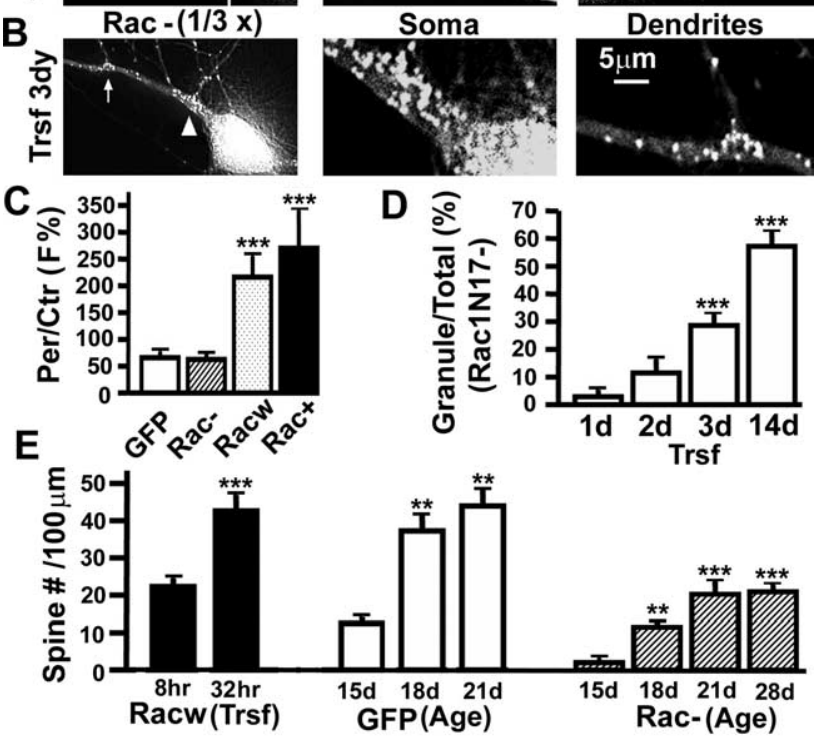

D $\odot 70$ -
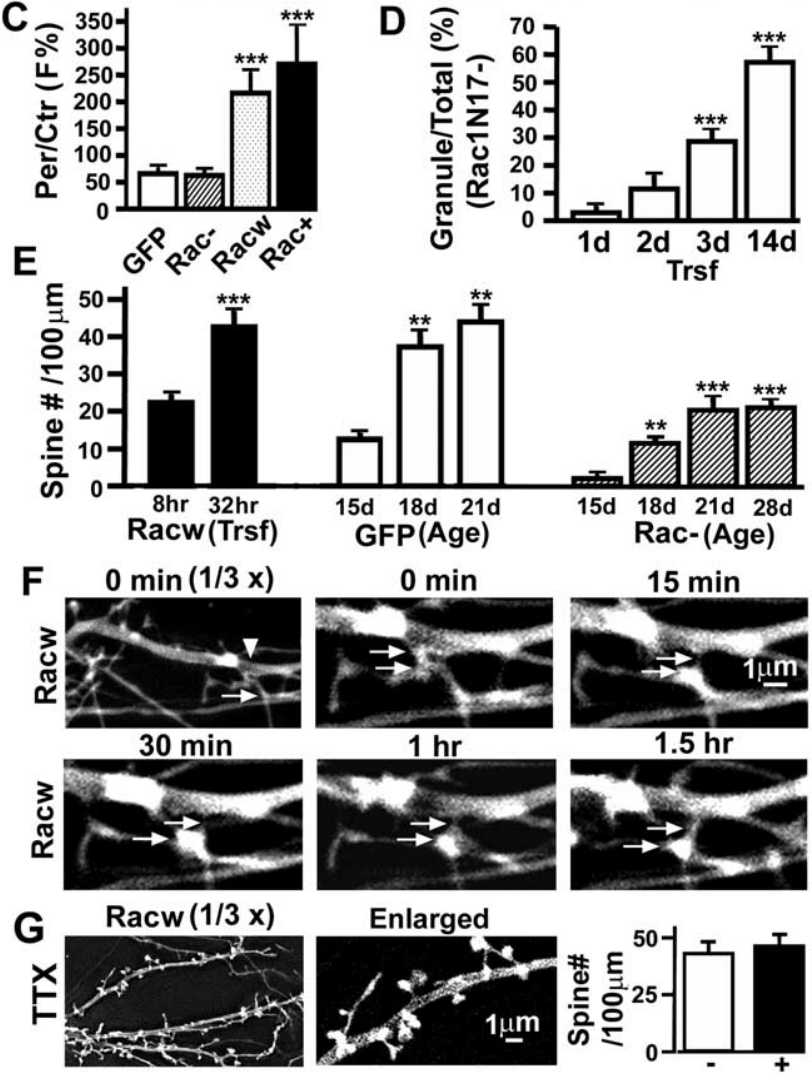

\section{Enlarged}
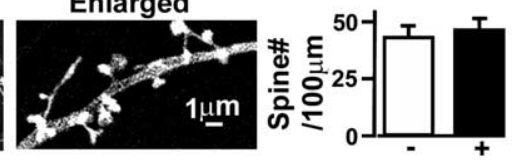

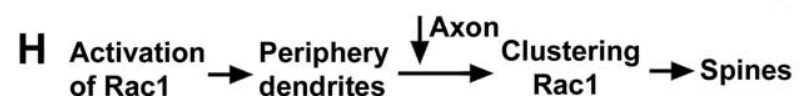

Figure 4. Temporal steps in Rac1-dependent formation of dendritic spines. A, Images of neurons were taken $8 \mathrm{~h}$ after transfection. Racw and $\mathrm{Rac}+$ were concentrated in the periphery of dendrites, whereas Rac - was concentrated in the center (arrowheads). Racw induced spinogenesis and clustered in spine heads, whereas Rac + induced random lamellipodia and clustered in their edges (arrows). $\boldsymbol{B}$, A neuron $3 \mathrm{~d}$ after the transfection of $\operatorname{Rac}-$. Rac - clustered in discrete granules at the proximal (arrowhead) and distal (arrow) dendrites. $\boldsymbol{C}$, The ratio of fluorescence (F) intensity in the periphery of dendrites versus the middle of dendrites (Per/Ctr) in four groups of neurons. $\boldsymbol{D}$, The proportion of neurons that contained granules versus the total number of neurons expressing Rac - in various days after transfection. $\boldsymbol{E}$, The density of spines in neurons expressing Racw (at 8 and $32 \mathrm{~h}$ after transfection), GFP (15-21 DIV), and Rac(15-28 DIV). Trsf, Time after transfection. Error bars represent SE. ${ }^{* *} p<0.01$; ${ }^{* *} p<0.001$. $\boldsymbol{F}$, Time-lapse images of a neuron expressing Racw showing how the contact of an axon led to spinogenesis. G, Spines were still formed in the presence of TTX in neurons $32 \mathrm{~h}$ after transfection of Racw. Right, Spine density in the presence $(+)$ and absence $(-)$ of TTX. $\boldsymbol{H}$, A model based on results in this figure shows how Rac1 initiates the formation of dendritic spines.

dependent synaptic plasticity (Maletic-Savatic et al., 1999; Matsuzaki et al., 2004) or by homeostatic regulation (Turrigiano et al., 1998; Turrigiano and Nelson, 2004). To test whether synaptic activity is required for the Rac1-initiated formation of dendritic spines, TTX was added to cultured media to block sodium channels in neurons expressing Racw. Images of neurons at 7 DIV were taken $32 \mathrm{~h}$ after transfection in the continuous presence of 
TTX. Neurons expressing Racw with no TTX treatment were used as a control. As shown in Figure 4G, the expression of Racw could still induce spinogenesis in the presence of TTX, and there was no significant difference in spine density between neurons with or without TTX treatment, indicating that the formation of spines in neurons expressing Racw does not require synaptic activity.

The clustering of active Racl is known to promote the growth of lamellipodia in fibroblasts (Ridley et al., 1992). In our study, Rac + randomly induced lamellipodia in neurons and clustered at the edge of these formations (Fig. 2G). Therefore, the axon-induced clustering of Racw (Fig. 4F) is also likely to induce the extension of the dendritic membrane, because Racl might be activated by Ephrin B from the contacting axon (Penzes et al., 2003). Based on the above data, we propose the following molecular model (Fig. $4 H$ ): in step 1, activated Rac1 mobilizes to the dendritic membrane. In step 2, the contact of an axon induces the clustering of Racl, causing changes in the actin cytoskeleton and pushing the cluster away from the dendrite to form a spine.

\section{Developmental changes in the expression level of endogenous Racl}

If Racl is in fact responsible for initiating spinogenesis, we would expect to see a developmental change in the amount of endogenous Rac1 present in neuronal cultures. To test this possibility, we ran Western blots using a mouse anti-Racl antibody to detect endogenous Racl in homogenized tissue from dissociated hippocampal cultures at 4-21 DIV (Fig. 5A, left panel, bottom bands). As shown in Figure $5 A$, cultures at 21 DIV had a higher expression level of endogenous Racl (38\%) than cultures at 4 DIV (15\%), 7 DIV (23\%), and 14 DIV (30\%). In addition, neurons at 7 DIV were faintly and diffusely stained by the anti-Rac1 antibody in immunocytochemistry (Fig. 5B). In contrast, endogenous Rac1 clustered in dendritic spines in neurons at 21 DIV, and these spines colocalized with synaptophysin and AMPARs (Fig. 5C). All of these results support the idea that the absence of dendritic spines during early neuronal development is attributable at least in part to an insufficient amount of Rac1.

\section{Rac1 modulates the morphology and function of preexisting spines}

Small Rho GTPases, including Rac1, are proposed to play important roles in the maintenance and stability of preexisting dendritic spines (Nakayama et al., 2000; Tashiro and Yuste, 2004). One distinct feature of molecules that can modulate preexisting glutamatergic synapses is that these molecules are often clustered in dendritic spines (Malinow et al., 2000; Sheng, 2001). To test whether Racl does cluster in preexisting spines, neurons at 21 DIV were transfected with GFP, Racw, Rac--, and Rac + using the standard gene gun technique (Wellmann et al., 1999). Racw and $\mathrm{Rac}+$ clustered in dendritic spines, whereas GFP and Rac- did not (Fig. 6A,B), suggesting that the clustering of Racl in spines requires the activation of $\mathrm{Racl}$. Rac + significantly increased the size of dendritic spines by $163 \%$, and Racw increased it by $109 \%$ $(n=8 ; p<0.001)$ (Fig. $6 C)$, suggesting a regulatory role of Rac1 in preexisting spines. Miniature EPSCs were recorded in neurons transfected with the gene gun to test how the activity of Racl affects the function of preexisting spines, and neurons transfected with GFP were used as a control (Fig. 6D-H). Consistent with the morphological changes, Rac + and Racw significantly increased the amplitude of mEPSCs $(n=8 ; p<0.05)$ (Fig. $6 E)$, indicating that the activation of Racl can drive functional AMPARs to preexisting synapses, possibly by increasing anchoring sites. Surprisingly, Rac - failed to cause any significant changes in spine size or mEPSC amplitude compared with control GFP. It has been shown previously that the expression of Rac- decreases the size and density of dendritic spines (Nakayama et al., 2000). This discrepancy is probably attributable to the difference in the expression time of $\mathrm{Rac}-$ and the age of neurons in our studies. Our recordings were taken within $24 \mathrm{~h}$ of transfection. Rac- can only block further activation of endogenous Rac1, and it is possible that previously activated endogenous Racl was not deactivated within this time period. Our neurons (21 DIV) were more mature than neurons in previous studies [P8 in brain slices (Nakayama et al., 2000)]. According to Grutzendler et al. (2002), the structure of dendritic spines in neurons that are older than 3 weeks is very stable. Breaking down the structure of preestablished dendritic spines may take longer than $24 \mathrm{~h}$, and we are therefore unable to detect any differences in our experimental model. The high variation in the frequency of mEPSCs is potentially caused by various degrees of cell death after gene gun transfection and might mask the difference among experimental groups (Fig. $6 F$ ). These discrepancies should not affect our conclusions on the role of Rac1 in AMPAR trafficking, because the amount of AMPARs per synapse should be determined mainly by the amplitude of mEPSCs. Overall, these results indicate that the activation of Racl can modulate both the morphology and function of preexisting spines. 
A

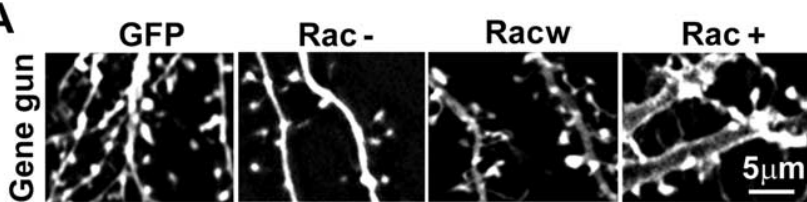

B

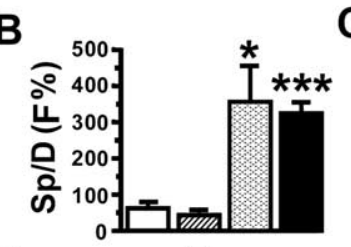

D
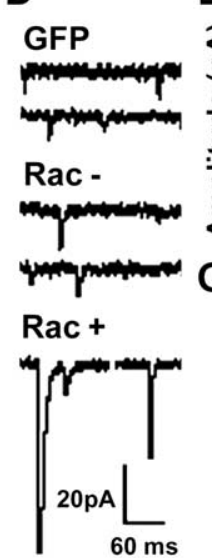

E

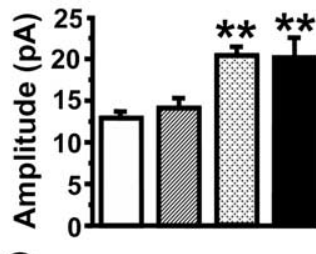

$F$

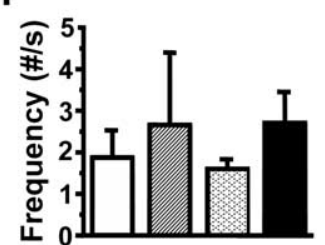



C

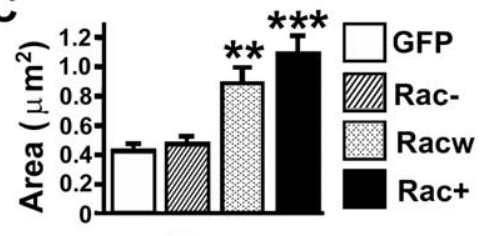

I

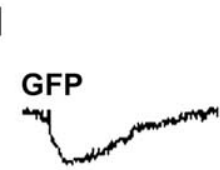

Rac-
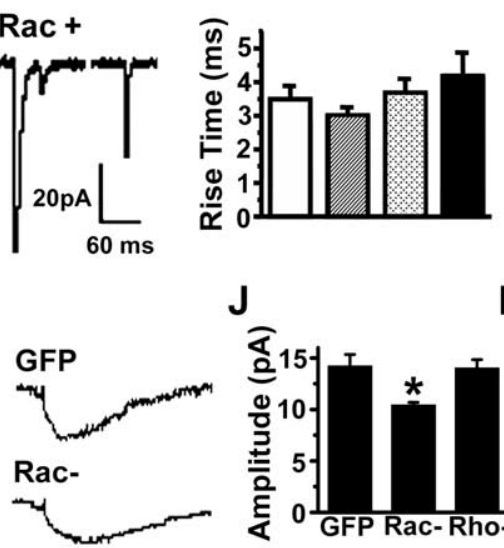

H

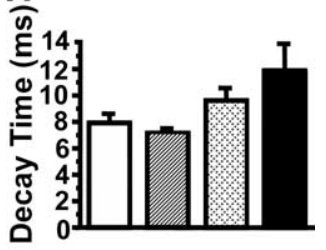

$\mathrm{J}$

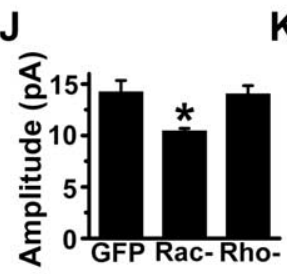

K
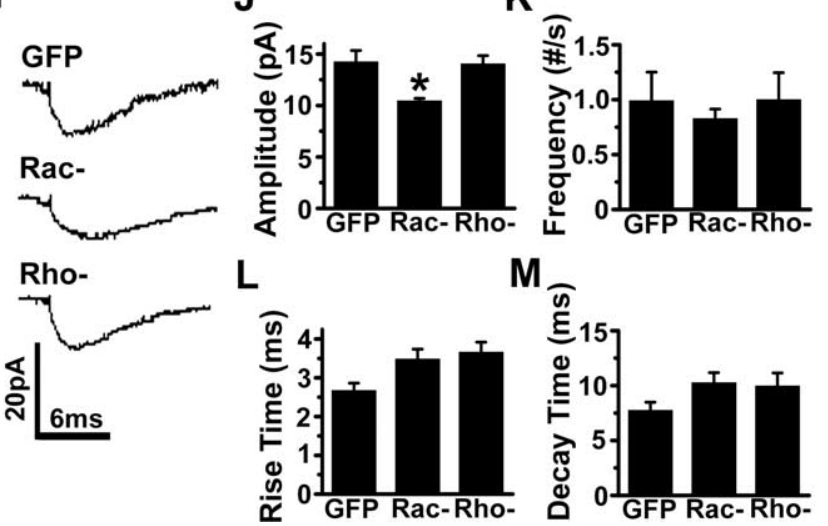

Figure 6. Rac1 regulates both the morphology and function of preexisting spines. $A$, Images of neurons at 21-22 DIV were taken $1 \mathrm{~d}$ after transfection with a gene gun. $\boldsymbol{B}$, Ratio of fluorescence (F) intensity in spines versus dendrites (Sp/D) in four groups of neurons. Open bar, GFP; hatched bar, Rac - ; dotted bar, Racw; black bar, Rac + . C, The size of dendritic spines in four groups of neurons. $\boldsymbol{D}$, Representative traces recorded from neurons transfected using the gene gun. $\boldsymbol{E}-\boldsymbol{H}$, The amplitude, frequency, rise time, and decay time of $\mathrm{mEPSC}$ in four groups of neurons. I, Averaged traces of neurons transfected at 5-7 DIV with GFP, Rac - , and Rho - and recorded at 17-21 DIV. J-M, The amplitude, frequency, rise time, and decay time of neurons represented in $I$. Rac - was able to decrease the mEPSC response, whereas Rho - was not. Error bars represent SE. ${ }^{*} p<0.05 ;{ }^{* *} p<0.01 ;{ }^{* * *} p<0.001$.

To further test how Racl affects the function of spines in mature neurons, we transfected neurons at 5-7 DIV with Racusing calcium phosphate precipitation and examined the necessity of Racl in the mediation of AMPARs during development. To test whether Rac- had the ability to reduce the AMPAR response in the few spines that were present at 21 DIV (Fig. $4 E$ ), we recorded mEPSCs at 17-21 DIV from neurons expressing Rac-. There was a significant decrease in the amplitude of AMPARmediated mEPSCs in neurons expressing Rac- compared with control neurons expressing GFP and no significant changes in frequency, rise time, or decay time (Fig. $6 I-M$ ). This result indicates that the few spines present at 21-28 DIV in neurons expressing Rac- (Fig. 4A, B,E) have fewer AMPARs at the postsynaptic membrane. To determine whether the effect of the dominantnegative mutant was specific to Rac1, we transfected neurons at 5-7 DIV with a dominant-negative form of RhoA (RhoAN19; referred to as Rho-). Rho- was not able to decrease the amplitude of the AMPAR-mediated mEPSCs (Fig. 6I-M). This result suggests that the decrease in AMPARs at the postsynaptic membrane of mature neurons expressing $\mathrm{Rac}^{-}$is specific to the dominant-negative form of Racl.

Rac1 acts via CRIB motif-containing proteins to induce the formation of dendritic spines and the clustering of AMPARs To further elucidate the downstream mechanism by which Rac1 induces the formation of dendritic spines and the clustering of AMPARs, we used EGFP-tagged Rac40, a mutant of Rac1 that disrupts its activation of CRIB motif-containing proteins such as PAK (Lamarche et al., 1996; Li et al., 1999). In neurons at 8 DIV, Rac40 was able to localize to the periphery of dendrites but was not able to induce the formation of dendritic spines (Fig. 7A,D), as seen with Racw (Figs. 1, 7D). Neurons transfected with Rac40 also had abnormally long filopodial protrusions compared with GFP and Racw (Fig. 7A,B). These long protrusions could be caused by two possible mechanisms. The first possibility is that inhibition of the interaction between Racl and CRIB motifcontaining proteins promotes the extension of filopodia. The second possibility is that Racl activates another signaling pathway that is independent of CRIB motif-containing proteins. Rac - should inhibit all Racl-dependent signaling pathways, including the interaction between Racl and CRIB motif-containing proteins. Because Rac - did not change the length of protrusions (Fig. $7 B$ ), this suggests that the Rac40-induced increase in protrusion length is more likely caused by an alternative pathway that does not involve CRIB motif-containing proteins. These long protrusions in neurons expressing Rac40 possessed significantly less AMPARs than those of neurons expressing Racw (Fig. $7 C, E)$. To test how Rac40 affects the function of excitatory synapses, mEPSCs were recorded at 7-11 DIV in neurons expressing GFP, Racw, or Rac40 (Fig. 7F-I). In contrast to Racw, Rac40 did not increase the amplitude or the frequency of mEPSCs. In fact, Rac40 significantly decreased the frequency compared with control GFP ( $n=8$ for all groups; $p<0.05$ ). Thus, disruption of the interaction between Racl and proteins containing the CRIB motif (e.g., PAK) attenuated the effects seen with Racw, indicating that CRIB proteins act downstream of Racl to induce the early formation of dendritic spines and the clustering of AMPARs in neurons expressing Racw.

\section{Discussion}

The majority of excitatory synaptic transmission occurs at glutamatergic synapses and is mediated via the AMPA-, NMDA-, and kainate-type glutamate receptors (Hollmann and Heinemann, 1994). NMDA receptors are essential for synaptic plasticity, such as long-term potentiation (LTP) and long-term depression (LTD) of glutamatergic synapses (Bliss and Collingridge, 1993; Malenka, 1994; Katz and Shatz, 1996). Both LTP and LTD can modulate synaptic strength by regulating AMPAR trafficking (Shi et al., 1999; Brown et al., 2005). AMPARs ultimately determine synaptic strength of glutamatergic synapses under normal conditions, because NMDA receptors are not activated at a nor- 
mal resting potential (Mayer et al., 1984; Liao et al., 1995; Isaac et al., 1995; Durand et al., 1996). Rho GTPases, including Rac1, Cdc42, and RhoA, have been reported widely to modulate the morphology of dendritic spines (Luo, 2000). However, little is known about the regulatory roles of these small GTPases in the function of excitatory synapses, particularly in the trafficking of AMPARs. Furthermore, the temporal dynamics of Racldependent spinogenesis is primarily unknown.

This study provides direct evidence that Racl can induce the clustering of AMPARs in both newly formed spines (Figs. 1, 2, 3) and preexisting spines (Fig. $6)$. Consistent with these morphological results, the overexpression of wild-type Racl and constitutively Racl increased the amplitude of mEPSCs, providing functional evidence that Racl can increase the amount of AMPARs per synapse. Interestingly, the expression of constitutively active Racl induced the strong clustering of AMPARs in the soma and the shaft of proximal dendrites even in the absence of dendritic spines (Figs. 2, 3). In fact, many AMPAR clusters colocalized with clusters of wild-type Racl on dendritic shafts (Figs. 1, $3)$. These two results indicate that the Rac1induced clustering of AMPARs does not result simply from the formation of spines.

The cellular mechanism underlying Racl-induced synaptic recruitment of AMPARs is unknown. Racl is known to regulate actin polymerization (Hall, 1998), and actin is essential for the anchoring of postsynaptic receptors such as NMDA, AMPA, and GABA receptors (Allison et al., 1998). Therefore, Racl is likely to indirectly cause clustering of AMPARs by increasing available anchoring sites in the actin cytoskeleton. Previous studies reveal that small GTPases such as Ras, Rap, and Rab can regulate AMPAR trafficking during LTP and LTD (Zhu et al., 2002; Brown et al., 2005). It is interesting that another small GTPase, Rac1, might regulate AMPAR trafficking in a different way by possibly altering the anchoring sites of postsynaptic receptors.

This study also provides direct evidence that Racl participates in spinogenesis during early neuronal development. Racl has been reported to modulate the maintenance of spines, as seen when altered Racl activity changes the density and size of dendritic spines (Nakayama et al., 2000). This previous observation could be attributable to changes in either spinogenesis or the maintenance of spines. As shown in Figure 1, the expression of Racw
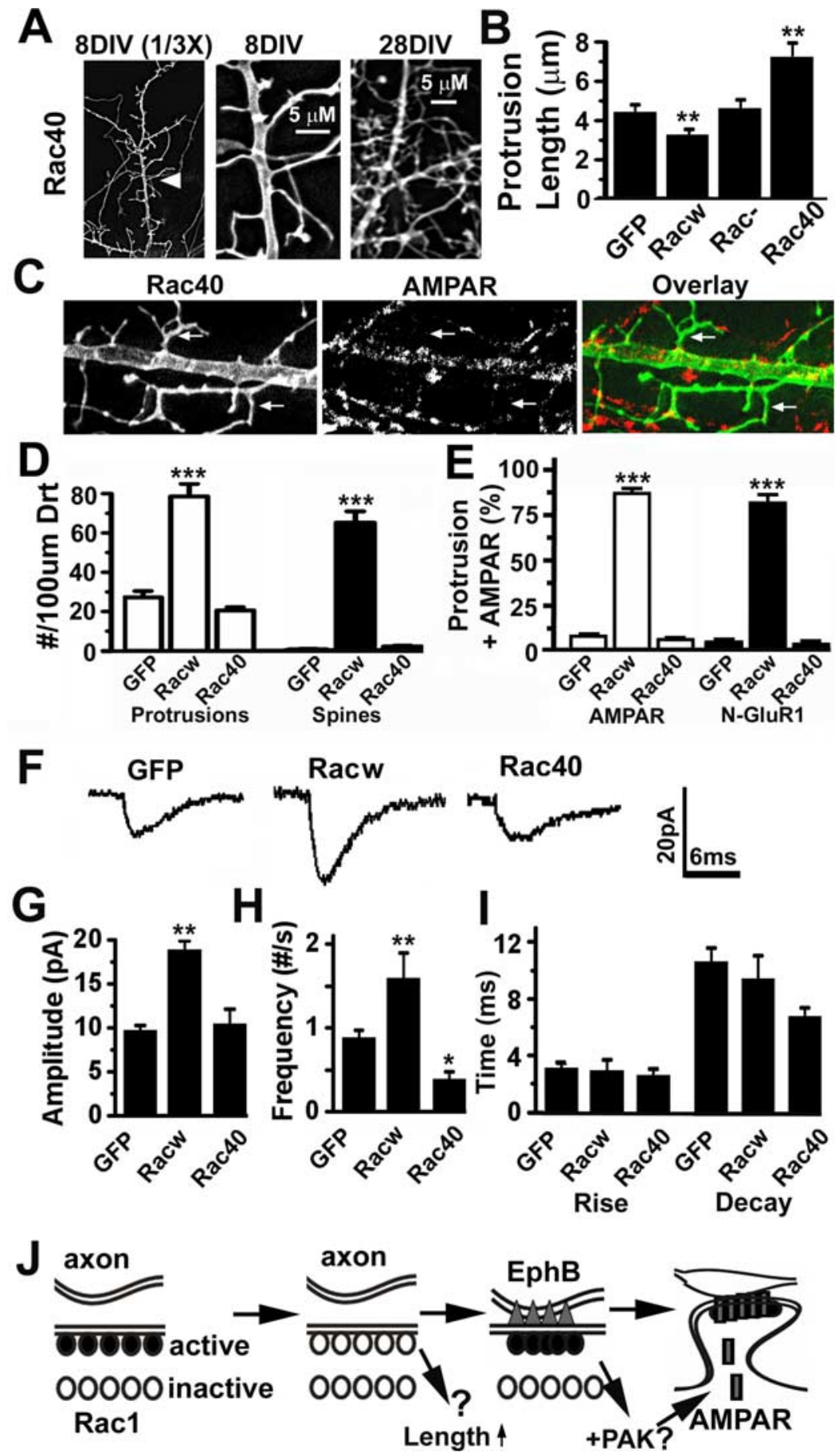

Figure 7. Rac1 acts via CRIB motif-containing proteins to induce the formation of dendritic spines and the clustering of AMPARs. A, Left, An 8 DIV neuron expressing a Rac1 mutation (Rac1Y40K) that disrupts the activation of CRIB motif-containing proteins such as PAK. The arrowhead indicates the enlarged area in the middle panel. Middle, Enlarged image of the area at the arrowhead in the left panel. Right, Enlarged image of a 28 DIV neuron expressing Rac40. Note the unusually long filopodia. $\boldsymbol{B}$, Rac40 increased the length of protrusions, whereas Racw decreased the length in neurons 7-11 DIV. C, AMPAR (GluR1 and GluR2/3) staining of a neuron expressing Rac40 at 8 DIV. The arrows denote the lack of AMPARs in the protrusions from the dendrite. $D$, Number of protrusions and spines [normalized to $100 \mu \mathrm{m}$ length of dendrite (Drt)] of neurons expressing GFP, RacW, and Rac40. E, Percentage of protrusions containing AMPAR clusters. Open bars, Total AMPARs were detected with two antibodies against GluR1 and GluR2/3. Solid bars, Surface AMPARs were detected with an antibody against N-GluR1. F, Average traces of mEPSC recordings of GFP, Racw, and Rac40. G-I, mEPSC amplitude, frequency, rise time, and decay time for neurons expressing GFP, Racw, and Rac40. Error bars represent SE. ${ }^{*} p<0.05$; ${ }^{* *} p<0.01$; ${ }^{* * *} p<0.001$. J, A model that incorporates previously reported studies indicates that the cycling of Rac1 between active and inactive states is important for normal spinogenesis (Symons and Settleman, 2000). Active Rac1 molecules are mobilized to submembrane spaces in the dendrites (step 1), and these molecules might be inactivated after they bind to membrane proteins (step 2). Ephrin B from an axon activates Eph B receptors and Kalirin, which then cluster and activate Rac1 (step 3). Finally, the clustering of activated Rac1 activates downstream effector proteins that have (RIB motifs (e.g., PAK) and leads to the formation of spines and an increase in the anchoring sites for AMPARs (step 4). 
alone can induce the formation of dendritic spines in neurons as young as 7 DIV. Our results indicate that Racl is a significant piece of the cellular machinery of spinogenesis and that this piece is missing in immature neurons. Consistent with this result, the expression level of endogenous Racl is indeed much lower in neurons at 7 DIV than neurons at 21 DIV (Fig. 5). Synaptic plasticity can modulate both the function and architecture of dendritic spines (Carlisle and Kennedy, 2005). Nevertheless, the overexpression of wild-type molecules that are known to participate in synaptic plasticity (CaM kinase II, GluR1, GluR2, NR1, and NR2B) cannot induce spinogenesis in neurons at 7 DIV (Shen and Meyer, 1999; Shi et al., 1999; Passafaro et al., 2003; Scott et al., 2004). As shown in Figure 5, TTX had no obvious effect on spinogenesis in neurons expressing wild-type Rac1, indicating that synaptic activity is not required for Racl-induced spinogenesis during early neuronal development. The Rac1-GEF Tiam 1 has been reported to couple the NMDA receptor to the activity-dependent development of dendritic arbors and spines (Tolias et al., 2005). The Rac1/PAK signaling pathway has been proposed to be important for de novo spine formation and spine splitting during synaptic plasticity (Hayashi et al., 2004). Although synaptic activity is not required in early spinogenesis, it is likely that NMDA receptor-dependent synaptic plasticity might still be able to modulate spinogenesis by acting on Rac1.

Our live imaging experiments have enabled us to determine the temporal processes that occur during Rac1-dependent spinogenesis (Fig. 4). The activation of Racl mobilizes Racl to submembrane spaces (Fig. $4 A, H$ ). The contact of an axon with a dendrite induces the clustering of Rac1 molecules that are already close to the cell surface (Fig. 4). The continuous accumulation of Racl pushes the axon and the clustered Racl molecules away from the dendrites and eventually leads to the formation of dendritic spines. As discussed previously, accumulated Racl can induce the clustering of functional AMPARs. Consequently, the newly formed dendritic spines would become mature excitatory synapses by acquiring AMPARs. The temporal steps in spinogenesis are still controversial, and there are two main competing theories (Nimchinsky et al., 2002). In the first theory, dendrites extend thin, thread-like filopodia, which contact axons and become mushroom-like dendritic spines. In the second theory, dendritic spines are formed directly from the dendritic shaft. Our live imaging data clearly support the second theory (Fig. 4), although the first possibility cannot be ruled out.

As discussed previously, one critical step in spinogenesis is the clustering of Racl, which is induced by the contact of an axon with a dendrite. However, the cellular mechanism that underlies this clustering of Rac1 is still unknown. It is well documented that axons express the B subtype of ephrins, which are cell-surface membrane-bound ligands to EphB receptors (Henkemeyer et al., 1996; Klein, 2004; Carlisle and Kennedy, 2005). EphB receptors are postsynaptic tyrosine kinase-linked receptors (Torres et al., 1998). Two recent papers have established that the Ephrin $\mathrm{B} / \mathrm{EphB}$ receptor signaling pathway is essential for the formation of normal dendritic spines. Henkemeyer et al. (2003) demonstrated that in EphB1, EphB2, and EphB3 triple knock-out mice, dendritic spines are absent in cultured hippocampal neurons and are grossly abnormal in vivo. Penzes et al. (2003) showed that treatment of neurons with ephrin-B1 causes the clustering and activation of EphB receptors and Kalirin 7 and increases the density of dendritic spines. Kalirin 7 is a Rac1-specific GEF that is essential for the normal formation of dendritic spines (Penzes et al., 2001). Also, the Rac/PAK signaling pathway plays an impor- tant role in the normal formation of dendritic spines in both intact animals and in cultured neurons (Hayashi et al., 2004; Zhang et al., 2005). Together, these previous studies have established that the Ephrin B/EphB receptor/Kalirin 7/Rac1/PAK signaling pathway is essential for the normal formation of dendritic spines (Carlisle and Kennedy, 2005). Here, we have elucidated three critical steps downstream of this signaling pathway (see our model in Fig. $7 J$ ). (1) Racl is clustered in the dendrites and drives the extension of dendritic spines. (2) The clustering of Racl induces the clustering of AMPARs, which enables newly formed spines to become functional. (3) A signaling pathway dependent on CRIB motif-containing proteins induces the clustering of AMPARs and the expansion of spine heads, whereas an unknown pathway that is independent of CRIB proteins might modulate the length of dendritic protrusions (Fig. 7J).

Glutamate receptors, protein kinases, and PDZ domaincontaining proteins are well known molecules that play critical roles in modulating the morphology and function of glutamatergic synapses (Malinow et al., 2000; Sheng, 2001; Bredt and Nicoll, 2003). One distinct feature of these molecules is that they often cluster in dendritic spines. As shown in Figures 5 and 6, Rac1 clusters in dendritic spines, and this clustering is dependent on the activation of Racl. This distinct feature of Racl strongly suggests that Racl modulates the morphology and function of preexisting spines. Indeed, the activation of Racl increased the size of dendritic spines (Fig. 6C) and the amplitude of mEPSCs (Fig. 6E).

This study indicates that the cycling of Racl between an active and an inactive state is needed to induce the proper formation of new spines (see model in Fig. $7 J$ ). Racl needs to be activated to be mobilized to the plasma membrane and then inactivated to prevent excessive and abnormal extension of lamellipodia. Based on our results, we suggest that the contact of an axon locally activates Rac1 through the EphB/Rac1/PAK pathway during spinogenesis (Figs. 4, 7), and Racl is then inactivated to prevent the excessive expansion of dendritic spines. However, a small proportion of Rac1 might need to be activated again during the maintenance of dendritic spines (Nakayama et al., 2000; Tashiro and Yuste, 2004). Overall, this study provides a valuable functional analysis of the roles of Racl in spinogenesis and the modulation of preexisting spines and has elucidated two critical cellular processes during spinogenesis: Racl-induced extension of spines and Rac1-induced clustering of AMPARs (see our model in Fig. 7J).

\section{References}

Adams AE, Johnson DI, Longnecker RM, Sloat BF, Pringle JR (1990) CDC42 and CDC43, two additional genes involved in budding and the establishment of cell polarity in the yeast Saccharomyces cerevisiae. J Cell Biol 111:131-142.

Allison DW, Gelfand VI, Spector I, Craig AM (1998) Role of actin in anchoring postsynaptic receptors in cultured hippocampal neurons: differential attachment of NMDA versus AMPA receptors. J Neurosci 18:2423-2436.

Bliss TV, Collingridge GL (1993) A synaptic model of memory: long-term potentiation in the hippocampus. Nature 361:31-39.

Bredt DS, Nicoll RA (2003) AMPA receptor trafficking at excitatory synapses. Neuron 40:361-379.

Brown TC, Tran IC, Backos DS, Esteban JA (2005) NMDA receptordependent activation of the small GTPase Rab5 drives the removal of synaptic AMPA receptors during hippocampal LTD. Neuron 45:81-94.

Bryan B, Kumar V, Stafford LJ, Cai Y, Wu G, Liu M (2004) GEFT, a Rho family guanine nucleotide exchange factor, regulates neurite outgrowth and dendritic spine formation. J Biol Chem 279:45824-45832.

Carlisle HJ, Kennedy MB (2005) Spine architecture and synaptic plasticity. Trends Neurosci 28:182-187. 
Durand GM, Kovalchuk Y, Konnerth A (1996) Long-term potentiation and functional synapse induction in developing hippocampus. Nature 381:71-75.

Grutzendler J, Kasthuri N, Gan WB (2002) Long-term dendritic spine stability in the adult cortex. Nature 420:812-816.

Hall A (1998) Rho GTPases and the actin cytoskeleton. Science 279:509-514.

Harris KM, Kater SB (1994) Dendritic spines: cellular specializations imparting both stability and flexibility to synaptic function. Annu Rev Neurosci 17:341-371.

Hayashi ML, Choi SY, Rao BS, Jung HY, Lee HK, Zhang D, Chattarji S, Kirkwood A, Tonegawa S (2004) Altered cortical synaptic morphology and impaired memory consolidation in forebrain-specific dominantnegative PAK transgenic mice. Neuron 42:773-787.

Henkemeyer M, Orioli D, Henderson JT, Saxton TM, Roder J, Pawson T, Klein R (1996) Nuk controls pathfinding of commissural axons in the mammalian central nervous system. Cell 86:35-46.

Henkemeyer M, Itkis OS, Ngo M, Hickmott PW, Ethell IM (2003) Multiple EphB receptor tyrosine kinases shape dendritic spines in the hippocampus. J Cell Biol 163:1313-1326.

Hoffman GR, Nassar N, Cerione RA (2000) Structure of the Rho family GTP-binding protein Cdc42 in complex with the multifunctional regulator RhoGDI. Cell 100:345-356.

Hollmann M, Heinemann S (1994) Cloned glutamate receptors. Annu Rev Neurosci 17:31-108.

Hori Y, Kikuchi A, Isomura M, Katayama M, Miura Y, Fujioka H, Kaibuchi K, Takai Y (1991) Post-translational modification of the C-terminal region of the rho protein are important for its interaction with the membranes and inhibitory GDP/GTP exchange proteins. Oncogene 6:515-522.

Isaac JT, Nicoll RA, Malenka RC (1995) Evidence for silent synapses: implications for the expression of LTP. Neuron 15:427-434.

Katz LC, Shatz CJ (1996) Synaptic activity and the construction of cortical circuits. Science 274:1133-1138.

Kennedy MB (2000) Signal-processing machines at the postsynaptic density. Science 290:750-754.

Klein R (2004) Eph/ephrin signaling in morphogenesis, neural development and plasticity. Curr Opin Cell Biol 16:580-589.

Lamarche N, Tapon N, Stowers L, Burbelo PD, Aspenstrom P, Bridges T, Chant J, Hall A (1996) Rac and Cdc42 induce actin polymerization of G1 cell cycle progression independently of $\mathrm{p} 65^{\mathrm{PAK}}$ and the JNK/SAPK MAP kinase cascade. Cell 87:519-529.

Li R, Debreceni B, Jia B, Gao Y, Tigyi G, Zheng Y (1999) Localization of the PAK1-, WASP-, and IQGAP1-specifying regions of Cdc42. J Biol Chem 274:29648-29654.

Li Z, Aizenman CD, Cline HT (2002) Regulation of rho GTPases by crosstalk and neuronal activity in vivo. Neuron 33:741-750.

Liao D, Hessler NA, Malinow R (1995) Activation of postsynaptically silent synapses during pairing-induced LTP in CA1 region of hippocampal slice. Nature 375:400-404.

Liao D, Zhang X, O’Brien R, Ehlers MD, Huganir RL (1999) Regulation of morphological postsynaptic silent synapses in developing hippocampal neurons. Nat Neurosci 2:37-43.

Liao D, Scannevin RH, Huganir R (2001) Activation of silent synapses by rapid activity-dependent synaptic recruitment of AMPA receptors. J Neurosci 21:6008-6017.

Liao D, Lin H, Law PY, Loh HH (2005) Mu-opioid receptors modulate the stability of dendritic spines. Proc Natl Acad Sci USA 102:1725-1730.

Lin H, Huganir R, Liao D (2004) Temporal dynamics of NMDA receptorinduced changes in spine morphology and AMPA receptor recruitment to spines. Biochem Biophys Res Commun 316:501-511.

Luo L (2000) Rho GTPases in neuronal morphogenesis. Nat Rev Neurosci $1: 173-180$.

Malenka RC (1994) Synaptic plasticity in the hippocampus: LTP and LTD. Cell 78:535-538.

Maletic-Savatic M, Malinow R, Svoboda K (1999) Rapid dendritic morphogenesis in CAl hippocampal dendrites induced by synaptic activity. Science 283:1923-1927.

Malinow R, Mainen ZF, Hayashi Y (2000) LTP mechanisms: from silence to four-lane traffic. Curr Opin Neurobiol 10:352-357.

Matsuzaki M, Honkura N, Ellis-Davies GC, Kasai H (2004) Structural basis of long-term potentiation in single dendritic spines. Nature 429:761-766.

Mayer ML, Westbrook GL, Guthrie PB (1984) Voltage-dependent block by $\mathrm{Mg}^{2+}$ of NMDA responses in spinal cord neurons. Nature 309:261-263.
Nakayama AY, Harms MB, Luo L (2000) Small GTPases Rac and Rho in the maintenance of dendritic spines and branches in hippocampal pyramidal neurons. J Neurosci 20:5329-5338.

Nimchinsky EA, Sabatini BL, Svoboda K (2002) Structure and function of dendritic spines. Annu Rev Physiol 64:313-353.

O’Brien RJ, Mammen AL, Blackshaw S, Ehlers MD, Rothstein JD, Huganir RL (1997) The development of excitatory synapses in cultured spinal neurons. J Neurosci 17:7339-7350.

Passafaro M, Nakagawa T, Sala C, Sheng M (2003) Induction of dendritic spines by an extracellular domain of AMPA receptor subunit GluR2. Nature 424:677-681.

Penzes P, Johnson RC, Sattler R, Zhang X, Huganir RL, Kambampati V, Mains RE, Eipper BA (2001) The neuronal Rho-GEF Kalirin-7 interacts with PDZ domain-containing proteins and regulates dendritic morphogenesis. Neuron 29:229-242.

Penzes P, Beeser A, Chernoff J, Schiller MR, Eipper BA, Mains RE, Huganir RL (2003) Rapid induction of dendritic spine morphogenesis by transsynaptic ephrinB-EphB receptor activation of the Rho-GEF kalirin. Neuron 37:263-274.

Pilpel Y, Segal M (2004) Activation of PKC induces rapid morphological plasticity in dendrites of hippocampal neurons via Rac and Rhodependent mechanisms. Eur J Neurosci 19:3151-3164.

Rao A, Craig AM (1997) Activity regulates the synaptic localization of the NMDA receptor in hippocampal neurons. Neuron 19:801-812.

Ridley AJ, Paterson HF, Johnston CL, Diekmann D, Hall A (1992) The small GTP-binding protein rac regulates growth factor-induced membrane ruffling. Cell 70:401-410.

Robbe K, Otto-Bruc A, Chardin P, Antonny B (2003) Dissociation of GDP inhibitor and membrane translocation are required for efficient activation of Rac by the Dbl homology-pleckstrin homology region of Tiam. J Bio Chem 278:4756-4762.

Scott DB, Michailidis I, Mu Y, Logothetis D, Ehlers MD (2004) Endocytosis and degradative sorting of NMDA receptors by conserved membraneproximal signals. J Neurosci 24:7096-7109.

Shen K, Meyer T (1999) Dynamic control of CaMKII translocation and localization in hippocampal neurons by NMDA receptor stimulation. Science 284:162-166.

Sheng M (2001) Molecular organization of the postsynaptic specialization. Proc Natl Acad Sci USA 98:7058-7061.

Shi SH, Hayashi Y, Petralia RS, Zaman SH, Wenthold RJ, Svoboda K, Malinow R (1999) Rapid spine delivery and redistribution of AMPA receptors after synaptic NMDA receptor activation. Science 284:1811-1816.

Shirao T, Sekino Y (2001) Clustering and anchoring mechanisms of molecular constituents of postsynaptic scaffolds in dendritic spines. Neurosci Res 40:1-7.

Symons M, Settleman J (2000) Rho family GTPases: more than simple switches. Trends Cell Biol 10:415-419.

Tashiro A, Yuste R (2004) Regulation of dendritic spine motility and stability by Racl and Rho kinase: evidence for two forms of spine motility. Mol Cell Neurosci 26:429-440.

Tolias KF, Bikoff JB, Burette A, Paradis S, Harrar D, Tavazoie S, Weinberg RJ, Greenberg ME (2005) The Racl-GEF Tiam1 couples the NMDA receptor to the activity-dependent development of dendritic arbors and spines. Neuron 45:525-538.

Torres R, Firestein BL, Dong H, Staudinger J, Olson EN, Huganir RL, Bredt DS, Gale NW, Yancopoulos GD (1998) PDZ proteins bind, cluster, and synaptically colocalize with Eph receptors and their ephrin ligands. Neuron 21:1453-1463.

Turrigiano GG, Nelson SB (2004) Homeostatic plasticity in the developing nervous system. Nat Rev Neurosci 5:97-107.

Turrigiano GG, Leslie KR, Desai NS, Rutherford LC, Nelson SB (1998) Activity-dependent scaling of quantal amplitude in neocortical neurons. Nature 391:892-896.

Wellmann H, Kaltschmidt B, Kaltschmidt C (1999) Optimized protocol for biolistic transfection of brain slices and dissociated cultured neurons with a hand-held gene gun. J Neurosci Methods 92:55-64.

Zhang H, Webb DJ, Asmussen H, Niu S, Horwitz AF (2005) A GIT1/PIX/ $\mathrm{Rac} / \mathrm{PAK}$ signaling module regulates spine morphogenesis and synapse formation through MLC. J Neurosci 25:3379-3388.

Zhu JJ, Qin Y, Zhao M, Van Aelst L, Malinow R (2002) Ras and Rap control AMPA receptor trafficking during synaptic plasticity. Cell 110: 443-455. 